\title{
Effects of Dexamethasone, Clonidine, Tramadol and Nalbuphine on Fentanyl-Induced Hyperalgesia in Rats
}

\author{
Camila dos Santos Leite ${ }^{1,2}$, Naira Correia Cusma Pelógia ${ }^{3}$, Eliane Stevanato ${ }^{3}$, \\ Marília Hidalgo Uchôas ${ }^{3}$, Marta Helena Rovani Pires ${ }^{4}$, Oscar César Pires ${ }^{3}$
}

${ }^{1}$ Laboratory of Immunopharmacology and Molecular Biology, São Francisco University Medical School, Bragança Paulista, Brazil ${ }^{2}$ Laboratory of Cell and Molecular Tumor Biology and Bioactive Compounds, São Francisco University Medical School, Bragança Paulista, Brazil

${ }^{3}$ Laboratory of Pharmacology and Physiology, Medicine Department, Taubaté University, Taubaté, Brazil

${ }^{4}$ Vera Cruz Hospital, Campinas, Brazil

Email: camilayantony@gmail.com, cusmapelogia@gmail.com, eliane.stevanato@unitau.br, marilia.hidalgo@unitau.br, marta_helena5@hotmail.com,oscar.pires@unitau.br

How to cite this paper: dos Santos Leite, C., Pelógia, N.C.C., Stevanato, E., Uchôas, M.H., Pires, M.H.R. and Pires, O.C. (2021) Effects of Dexamethasone, Clonidine, Tramadol and Nalbuphine on Fentanyl-Induced Hyperalgesia in Rats. Journal of Biosciences and Medicines, 9, 87-97. https://doi.org/10.4236/jbm.2021.912007

Received: October 26, 2021

Accepted: December 10, 2021

Published: December 13, 2021

Copyright $\odot 2021$ by author(s) and Scientific Research Publishing Inc. This work is licensed under the Creative Commons Attribution International License (CC BY 4.0).

http://creativecommons.org/licenses/by/4.0/ (c) (i) Open Access

\begin{abstract}
Opioids are drugs used to alleviate pain. However, studies have demonstrated that these drugs can cause an increase in pain sensitivity, which is called opioid-induced hyperalgesia. The objective of this study was to describe the effects of dexamethasone, clonidine, tramadol and nalbuphine on fentanylinduced hyperalgesia in rats. After obtaining approval from the Committee for the Ethical Use of Animals (CEUA), 36 male Wistar rats were divided into 6 groups: Group 1 (GCSSL) wherein the rats received $1 \mathrm{ml} 0.9 \%$ saline solution in two injections; Group 2 (GFTSL), received fentanyl at a dose of 100 ug. $\mathrm{kg}^{-1}$ followed by $1 \mathrm{ml} 0.9 \%$ saline solution via intraperitoneal; the remaining groups $(3,4,5,6)$ received fentanyl at a dose of $100 \mathrm{ug} \cdot \mathrm{kg}^{-1}$ following doses via intraperitoneal: Group 3 (GFTDX), dexamethasone at a dose of $1.0 \mathrm{mg} \cdot \mathrm{kg}^{-1}$; Group 4 (GFTCL), clonidine at a dose of $20 \mathrm{mg} \cdot \mathrm{kg}^{-1}$; Group 5 (GFTTR), tramadol at a dose of $50 \mathrm{mg} \cdot \mathrm{kg}^{-1}$, and Group 6 (GFTNB), nalbuphine at a dose of $5 \mathrm{mg} \cdot \mathrm{kg}^{-1}$. Under general anestesia using isoflurane, the animals were submitted to a surgical incision. Hyperalgesia was evaluated by applying Von Frey filaments at 2 hours after the incision and on the $1^{\text {st }}, 3^{\text {rd }}$ and $5^{\text {th }}$ days afterward. At 2 hours after the surgical procedure, there was lower intensity of pain in the fentanyl group (GFTSL) compared to the other groups, and on the fifth day there were no significant differences for pain intensity between groups. The results suggest the presence of fentanyl-induced hyperalgesia and efficacy in its reduction by dexamethasone, clonidine, tramadol and nalbuphine.
\end{abstract}




\section{Keywords}

Hyperalgesia, Fentanyl, Dexamethasone, Clonidine, Tramadol, Nalbuphine, Rats

\section{Introduction}

Pain is one of the most important and complex human experiences and is defined by the International Association for the Study of Pain (IASP) as "disagreeable sensory or emotional experience associated with real or potential bodily injury" [1].

The use of opioids for pain treatment has increased in during recent years, and in some countries, they have become the most commonly prescribed drugs [2]. However, this increase has created problems such as abusive use, and several diverse events including fentanyl-induced hyperalgesia, a phenomenon wherein, paradoxically, the opiod can induce or make patients more sensitive to sharp pain [3] [4] [5]. In this situation, patients that receive opioids may experience significant post-operative sharp pain, thus causing greater tolerance to increasing doses and subsequent anxiety expressed by the patient as well as the doctor [4].

Among the supposed mechanisms responsible for hyperalgesia induced by opioids (HIO) are alterations in the N-methyl-D-aspartate (NMDA) receptors and secondary messengers, activation of spinal cyclooxygenase (COX), liberation of excitatory amino acids, reduction of inhibitory neurotransmissors, descending facilitation, and the anti-analgesic system [2] [3] [6].

The increased in the liberation of glutamate in the dorsal horn of the spinal cord and the subsequent maintained increase in the stimulus and response of NMDA receptors due to the removal of magnesium mediated by protein kinase $\mathrm{C}$ seem to be the principal mechanisms involved in HIO [7].

These NMDA receptors can be activated by opioids, which act as excitatory neurotransmissors causing na increase in calcium in the cell and centralized sensitivity. The entry of calcium into the cell provokes an increase in the activity of protein kinase $\mathrm{C}$, phosphorylation, and inactivation of opioid receptors, besides causing an increase in nitric oxide synthase [8].

HIO has been associated with an increase in cholecystokinin, for a peptide related to the gene calcitonin (CGRP), substance-P, and nociceptin in the rostral ventromedial medulla due to increase in expression of excitatory opioid receptors, in detriment inhibitory opioid receptors [9] [10] [11].

The descending facilitation pathways, mediated by opiods and located in the rostral ventromedial medulla, are also involved in HIO due to neuroplastic [12], since exposure to morphine causes neuroplastic alterations in the rostral ventromedial medulla with an increase in the liberation of dynorphin and neurotransmissors of primary afferent fibers [3]. In this context, the administration of an opioids causes an increase in dynorphin, which can favor HIO [9] [13]. 
There is evidence that spinal dynorphin is pronociceptive, causing liberation of excitatory neurotransmissors of primary afferent neurons, suggesting a positive feedback, thus amplifying sensitive afference [13]. Furthermore, prostaglandins, cytokines, and chemokines can also be relevant to the development of HIO since opioids activate the liberation of cytokines and cause an increase in c-FOS protein in sensitive neurons in the medulla. Another system that could be involved in HIO is the nitric oxide synthase system, along with hemoxygenase, which could reduce glycinergic inhibitory control [2] [3].

Among the steroidal anti-inflammatory drugs, some prevent sensitivity to nociceptors through inhibition of the phospholypase A2, and therefore of the entire cascade of arachidonic acid, inhibiting COX-1 as well as COX-2. These drugs appear to have a relevant role in inhibition of hyperalgesia through stimulation and recapture of glutamate in the dorsal horn of the spinal cord, besides blocking NMDA receptors, with dexamethasone having a smaller mineralocorticoid effect than other drugs in this group [3] [14].

Studies have examined the role of agonists of the $\alpha 2$ receptor in the modulation of HIO, and have shown that clonidine attenuated post-infusion hyperalgesia induced by opioids and eliminated secondary post-infusion hyperalgesia induced by opioids, suggesting participation of $\alpha 2$ receptors in the modulation of HIO [15].

Tramadol is an example of an analgesic that demonstrates multiple mechanisms of analgesic action through the combined action of the enantiomers of the original drug and the enantiomers of its metabolite O-desmethyl (M1), which has at least three mechanisms: affinity for the morphine opioid receptor, inhibition of neuronal recapture of norepinephrine, and inhibition of neuronal recapture of serotonin, and since these are chemically modified, they have a strong analgesic effect. In this sense, it has been suggested that tramadol could be useful in the prevention of HIO [16].

Nalbuphine is a agonist of the kappa ( $\kappa$ ) opioid receptor and na antagonist of the $\mathrm{mi}(\mu)$ receptor, which acts as a weaker analgesic, but which can retard or inhibit tolerance to morphine, besides inhibiting HIO [17].

In this sense, this study used adjuvants commonly used in anesthetic procedures, including the steroidal anti-inflammatory drug-dexamethasone, alpha2adrenergic agonist—clonidine, opioid agonist—-tramadol and the opioid agonist-antagonist-nalbuphine.

\section{Objective}

Describe the effects of the drugs: dexamethasone, clonidine, tramadol and nalbuphine on fentanyl-induced hyperalgesia in rats using a standard plantar surgical incision.

\section{Material and Methods}

\subsection{Animals}

A total of 36 male Wistar rats weighing between 220 and 300 grams was allo- 
cated in compartiments in groups of six. The rats remained in these compartiments for 15 days before the start of the experiment to adapt to the confined environment and were fed a nutritionally balanced commercial feed and water " $a d$ libitum", and were subjected to a 12-hour light-dark cycle with ambient temperature varying between $19^{\circ} \mathrm{C}$ and $25^{\circ} \mathrm{C}$.

\subsection{Ethical Aspects}

The experimental procedures followed the ethical standards of the International Association for the Study of Pain (IASP), which establishes the norms for animal experimentation (Commitee for Research and Ethical Issues of the IASP), and the study began only after having received approval from the Committee for the Ethical Use of Animals Use (CEUA) of Taubaté University, under protocol ( $\left.n^{\circ} 03 / 2017\right)$. All experiments were conducted in the Pharmacology Laboratory of the university.

\subsection{Anesthetic Induction}

To induce light anesthetic induction, the animals were placed in a $15 \times 25 \times 15$ $\mathrm{cm}$ transparent glass chamber with a transparent lid in order to observe the animals, and the chambre had an opening on the top and the bottom for entry and entry and exit of oxygen $\left(\mathrm{O}_{2}\right)$, anesthetic gases, and carbon dioxide.

The halogen agent used for anesthetic induction was isoflurane (Isoforine ${ }^{\circledR}$, Cristália, Itapira, Brazil), at a concentration of $4.0 \%$ in a 1.0 oxygen inspired fraction $\left(\mathrm{FiO}_{2}\right)$ of 1.0, administered using a calibrated vaporizer (HB Hospitalar) and maintained for 3 minutes, the time necessary so that the animal demonstrated loss of postural reflexes and inability to move within the chamber. Subsequently, the animal was removed from the chamber and positioned with the snout in a mask through which it continually received at $4 \%$ isoflurane in $\mathrm{O}_{2}$, as was done in the chamber where anesthesia was indeced.

\subsection{Surgical Incision}

The surgical procedure consisted of a $1.0 \mathrm{~cm}$ longitudinal incision on the right posterior paw, according to the post-operative pain model as described [18].

The incision was done using a scalpel with a number 11 blade, incising the skin and fascia the plantar of the paw, starting at $0.5 \mathrm{~cm}$ from the edge of the calcaneus and extending in the direction of the toes. Subsequently, the plantar muscle was elevated and longitudinally incised, with its insertion remaining intact. After hemostasis with light pressure on the surgical incision, all the planes were approximated and stiched with two separate stitches using needled thread mononylon 4-0.

\subsection{Experimental Design}

The animals were randomly divided into six groups $(n=6)$ and received equal volumes of drugs or $0.9 \%$ saline solution.

In group 1 (GCSSL) the rats received $1 \mathrm{ml} \mathrm{0.9 \%} \mathrm{saline} \mathrm{solution} \mathrm{in} \mathrm{two} \mathrm{injec-}$ 
tion via intraperitoneal (IP). Group 2 (GFTSL) received fentanyl at a dose of 100 ug. $\mathrm{kg}^{-1}$ followed by $1 \mathrm{ml} 0.9 \%$ saline solution via IP. The remaining groups $(3,4$, $5,6)$ received IP, fentanyl at a dose of $100 \mathrm{ug} \cdot \mathrm{kg}^{-1}$ and the following doses via IP: Group 3 (GFTDX), dexamethasone at a dose of $1.0 \mathrm{mg} \cdot \mathrm{kg}^{-1}$; Group 4 (GFTCL), clonidine at a dose of $20 \mathrm{mg} \cdot \mathrm{kg}^{-1}$; Group 5 (GFTTR), tramadol at a dose of 50 $\mathrm{mg} \cdot \mathrm{kg}^{-1}$, and Group 6 (GFTNB), nalbuphine at a dose of $5 \mathrm{mg} \cdot \mathrm{kg}^{-1}$.

\subsection{Mechanical Hyperalgesia}

The evaluation of hyperalgesia was done by applying von Frey filaments as conducted [18]. For the von Frey test, the animals were placed in a wooden chamber, with a floor of $0.5 \mathrm{~cm}$ checkered galvanized screen. A mirror was fixed to this floor so that the researchers could observe the application of the filament and the reflex of the member.

Before the application of the filaments the animals were maintained in the wooden chambers for about 15 minutes so they could adapt to the surroundings.

Each of the filaments, in decreasing order of pressure was applied three consecutive times with at intervals of 3 to 5 seconds, and a positive response was considered to be when the animal removed the incised member from the floor when the filament as applied.

When the animals had the incised member completely removed from the floor the value of pressure was registred as zero, meaming thet no stimulus was necessary for the animal to remove its member from contact with the floor.

The data were registered on separate tables for each animal at 2 hours, and 1 , 3 and 5 days after the surgical procedure and administration of the treatments. After evaluation of hyperalgesia the animals were euthanized through injection with sodium pentothal at a dose of $100 \mathrm{mg} \cdot \mathrm{kg}^{-1}$.

\subsection{Statistical Analysis}

Statistical analysis was done using the software JMP ${ }^{\circledR}$ from the Statistical Analysis System (SAS) Institute, using analysis of variance (ANOVA) followed by student's t-test comparing each pair at a probability level of $\alpha=5 \%$.

\section{Results}

There was no statistical difference for the mean weight of animals between groups ( $\mathrm{p}>0.05)$.

Pain intensity and standard deviation, assessed using the von Frey filaments in all studied groups and moments, is show in Table 1 and Figures 1-4.

At the second hour after the surgical procedure the pain intensity evaluated using the von Frey filaments is shown in Figure 1, showing a significant difference with a lower intensity of hyperalgesia in the group that received fentanyl (GFTSL) compared to the other groups.

At day one after the surgical procedure, pain intensity, as evaluated by the von Frey filaments, is shown in Figure 2, showing a significant difference with greater 
hyperalgesia in the group that received fentanyl (GFTSL) compared to the other groups.

Table 1. Pain intensity and standard deviation, using the von Frey filaments in the groups.

\begin{tabular}{llllllllll}
\hline Groups & \multicolumn{2}{c}{$\mathbf{2}^{\text {nd }}$ hour } & \multicolumn{2}{c}{$\mathbf{1}^{\text {st }}$ day } & \multicolumn{2}{c}{$3^{\text {rd }}$ day } & \multicolumn{2}{c}{$5^{\text {st }}$ day } \\
\hline & Means & SD & \multicolumn{2}{c}{ Means } & SD & Means & SD & Means & SD \\
\hline GCSSL & 2.93 & 0.47 & 3.98 & 0.64 & 4.37 & 0.43 & 4.66 & 0.56 \\
GFTSL & 4.04 & 0.39 & 2.68 & 0.69 & 2.88 & 0.47 & 4.71 & 0.44 \\
GFTDX & 3.37 & 0.63 & 4.93 & 0.19 & 4.86 & 0.62 & 5.09 & 0.50 \\
GFTCL & 2.81 & 0.36 & 4.25 & 0.70 & 5.20 & 0.67 & 5.22 & 0.45 \\
GFTTR & 3.02 & 0.40 & 5.22 & 0.32 & 5.50 & 0.31 & 5.31 & 0.49 \\
GFTNB & 2.76 & 0.29 & 4.37 & 0.43 & 5.15 & 0.45 & 5.06 & 0.45 \\
\hline
\end{tabular}

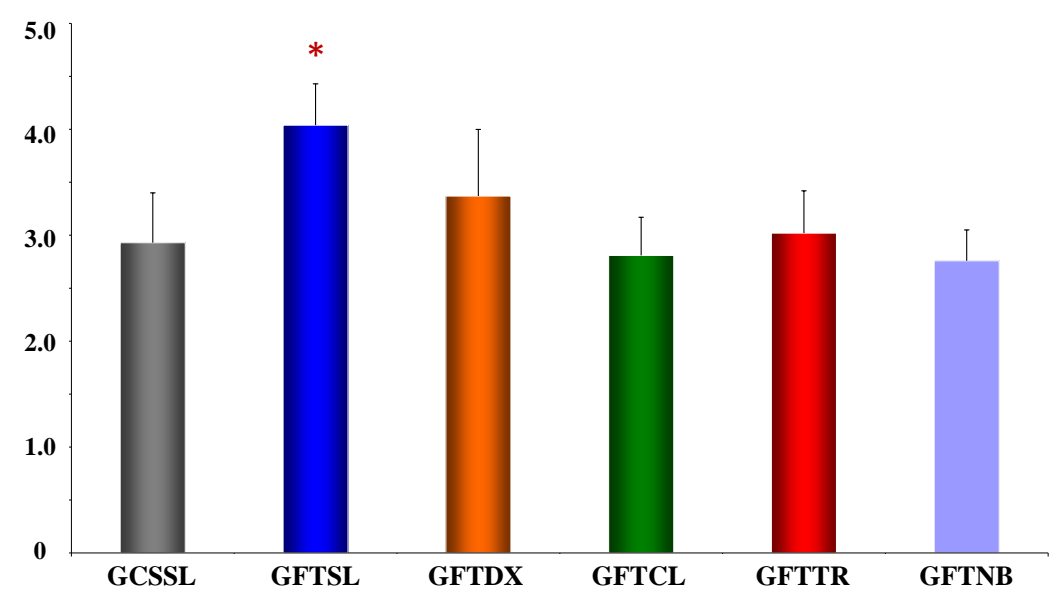

Figure 1. Pain intensity at the second hour after the surgical procedure for the groups: GCSSL, GFTSL, GFTDX, GFTCL, GFTTR and GFTNB. Student's t-test showing a significant difference compared to the fentanyl group (GFTSL ${ }^{*}$ ) compared to other groups $(\mathrm{p}<0.05)$.

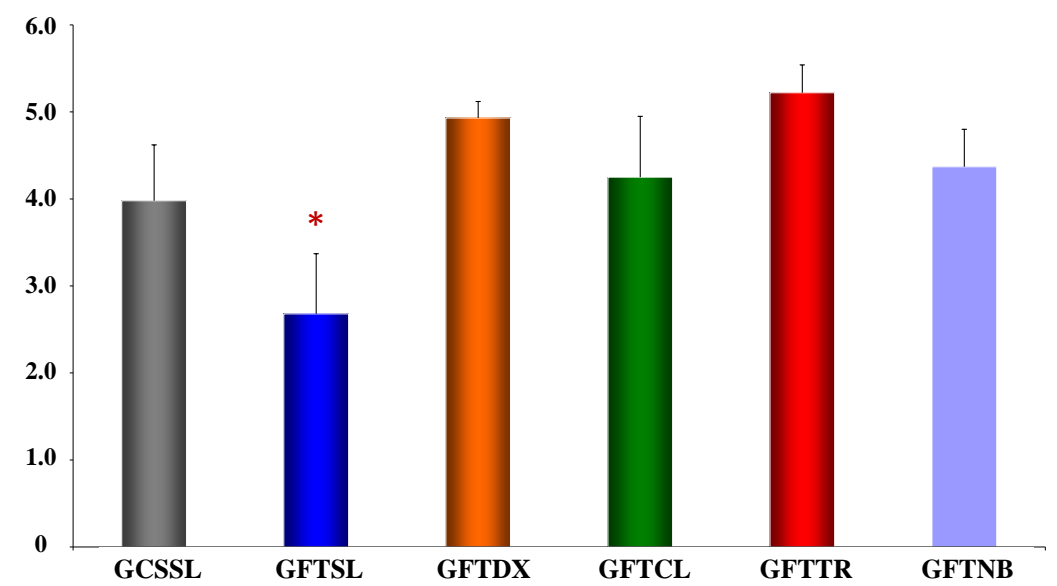

Figure 2. Pain intensity at the first day after the surgical procedure for the groups: GCSSL, GFTSL, GFTDX, GFTCL, GFTTR and GFTNB. Student's t-test showing a significant difference compared to the fentanyl group (GFTSL ${ }^{*}$ ) compared to other groups $(\mathrm{p}<0.05)$. 


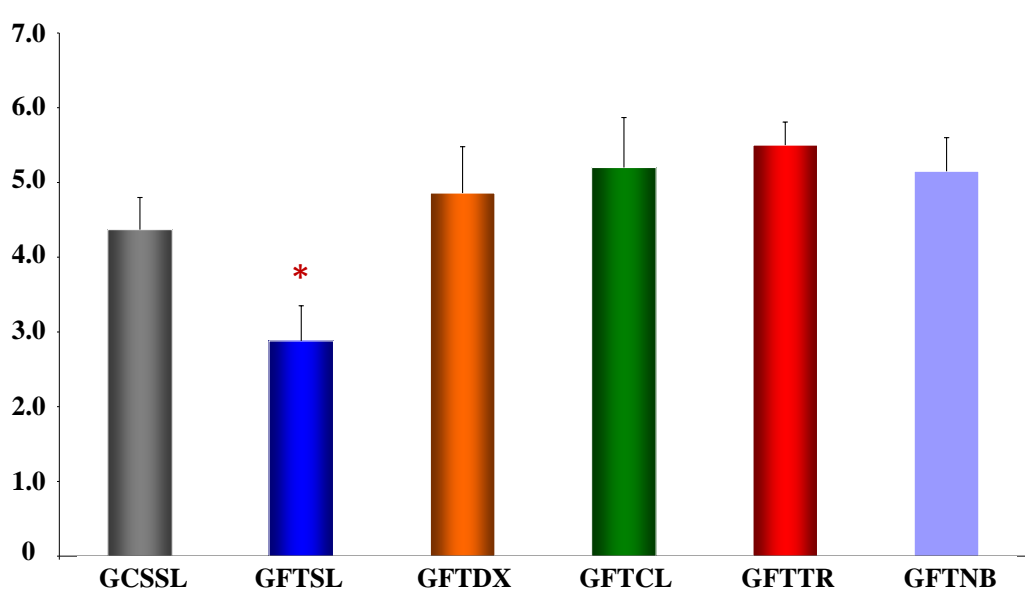

Figure 3. Pain intensity at the three day after the surgical procedure for the groups: GCSSL, GFTSL, GFTDX, GFTCL, GFTTR and GFTNB. Student's t-test showing a significant difference compared to the fentanyl group (GFTSL ${ }^{\star}$ ) compared to other groups $(\mathrm{p}<0.05)$.

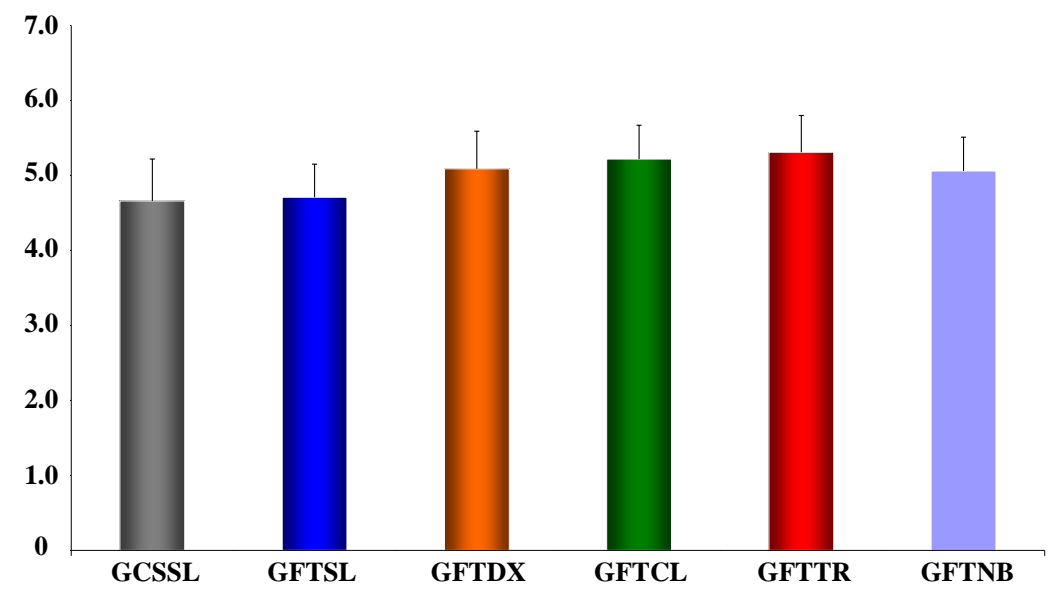

Figure 4. Pain intensity at the fifth day after the surgical procedure for the groups: GCSSL, GFTSL, GFTDX, GFTCL, GFTTR and GFTNB. Student's t test showing no significant differences between groups ( $p>0.05)$.

At day three after the surgical procedure, as in day one, pain intensity, as evaluated by the von Frey filaments, is shown in Figure 3, showing a significant difference with greater hyperalgesia in the group that received fentanyl (GFTSL ${ }^{\star}$ ) compared to the others groups.

At day fifth after the surgical procedure, pain intensity, as evaluated by the von Frey filaments, is shown in Figure 4, showing no significant differences with the other groups.

When the fentanyl-treated group was compared with the other groups, there was a significant difference in time points; $2^{\text {nd }}$ hour, with less pain intensity, evaluated by von Frey filaments in the fentanyl group, probably due to its acute analgesic effect, is shown in Table 2.

However, on the $1^{\text {st }}$ and $3^{\text {rd }}$ day there was greater pain intensity in the group that received fentanyl alone, suggesting opioid-induced hyperalgesia and pain 
Table 2. Comparative analysis between the group treated with fentanyl and the groups treated with saline solution and anesthetic adjuvants; dexamethasone, clonidine, tramadol and nalbuphine at the studied times.

\begin{tabular}{ccccc}
\hline Groups & $\mathbf{2}^{\text {nd }}$ hour & $\mathbf{1}^{\text {st }}$ day & $3^{\text {rd }}$ day & $\mathbf{5}^{\text {st }}$ day \\
\cline { 2 - 5 } & $\mathrm{p}$ & $\mathrm{p}$ & $\mathrm{p}$ & $\mathrm{p}$ \\
\hline GFTSL $\times$ GCSSL & 0.0015 & $<0.0001$ & $<0.0001$ & 0.6431 \\
GFTSL $\times$ GFTDX & 0.0487 & $<0.0001$ & $<0.0001$ & 0.0603 \\
GFTSL $\times$ GFTCL & 0.0005 & $<0.0001$ & $<0.0001$ & 0.0594 \\
GFTSL $\times$ GFTTR & 0.0033 & $<0.0001$ & $<0.0001$ & 0.0507 \\
GFTSL $\times$ GFTNB & 0.0003 & $<0.0001$ & $<0.0001$ & 0.0743 \\
\hline
\end{tabular}

There were significant differences between the fentanyl group (GFTSL ${ }^{*}$ ) and the other groups, in the $2^{\text {nd }}$ hour, $1^{\text {st }}$ and $3^{\text {rd }}$ days afterward $(\mathrm{p}<0.05)$. On the $5^{\text {th }}$ day, there were no significant differences.

reduction when the animals received the drugs used as adjuvants in anesthesia, suggesting hyperalgesia attenuation with the use of these drugs.

\section{Discussion}

Opioids are medicines that are fundamental to pain treatment, however, while at the beginning of treatment they are considered analgesics and anti-hyperalgesics, they can posteriorly provoke hyperalgesia, thus making the patient more sensitive to pain [2] [9].

Opioid-induced hyperalgesia has been attributed to acute desensitization of receptors due to the derailment of the $G$ protein of the opioid receptors, and activation of N-methyl-aspartate receptors, among other mechanisms [2].

Studies have shown that the concomitant use of low doses of opioid antagonists and antagonists of NMDA receptors can prevent or reduce development of HIO and that ketamine in low doses can modulate HIO [7] [19] [20].

Furthermore, it as been shown that mechanisms implicated in the development of HIO include the glutamatergic system and NMDA receptors, activation of spinal COX, excitatory amino acids, dynorphins, cytokines and chemokines, prostaglandins, and descending facilitation [6]. In this context, it can be conjectured that the modulation of hyperalgesia could be mediated by antagonists of NMDA receptors, alpha-2 adrenergic agonists, selective inhibitors of recapture serotonin, inhibitors of cyclooxygenases, analogous to GABA, and antagonists of $\mu$ opioid receptors [6] [21].

In this study, at the second hour after the surgical procedure, there was a greater analgesic effect in the group that received phenethyl, which can be explained by the more intense analgesic property of this drug [22].

When the animals were evaluated on the first and third day after the surgical procedure, the group that received fentanyl via IP showed a greater hyperalgesic effect with a significant statistical difference compared to the other groups that received fentanyl, and the drugs proposed in the study, thus demonstrating the 
possibility of opioid-induced hyperalgesia and antihyperalgesic effect of the drugs used in this study.

It is important to emphasize that the control group, although it did not show a hyperalgesic effect as did the animals in the fentanyl group, did not receive fentanyl, and probably did not develop HIO and therefore did not obtain the analgesic benefits provided by the opioid.

On the fifth day after the surgical procedure, there were no statistical differences between groups, meaning that there was no residual effect of hyperalgesia induced by a single dose of fentanyl. Even so, a reduction in algesic sensitivity was observed for all groups compared to the evaluations at 2 hours and days 1 and 3 , thus indicating possible conclusion of the algesic process.

\section{Conclusion}

The results obtained of this study suggest hyperalgesia induced by fentanyl and a possible attenuating effect mediated by the drugs dexamethasone, clonidine, tramadol and nalbuphine, and future studies should be conducted to further confirm and expand upon these findings.

\section{Conflicts of Interest}

The authors declare no conflicts of interest regarding the publication of this paper.

\section{References}

[1] Raja, S.N., Carr, D.B., Cohen, M., Finnerup, N.B., Flor, H., Gibson, S., Keefe, F.J., Mogil, J.S., et al. (2020) The Revised International Association for the Study of Pain Definition of Pain: Concepts, Challenges, and Compromises. Pain, 161, 1976-1982. https://doi.org/10.1097/j.pain.0000000000001939

[2] Kunnumpurath, S., Julien, N., Kodumudi, G., Kunnumpurath, A., Kodumudi, V. and Vadivelu, N. (2018) Global Suplly and Demand of Opioids for Pain Management. Current Pain and Headache Reports, 22, Article No. 34. https://doi.org/10.1007/s11916-018-0689-1

[3] Chu, L.F., Angst, M.S. and Clark, D. (2008) Opioid-Induced Hyperalgesia in Humans: Molecular Mechanisms and Clinical Considerations. The Clinical Journal of Pain, 24, 479-496. https://doi.org/10.1097/AJP.0b013e31816b2f43

[4] Silverman, S. (2009) Opioid Induced Hyperalgesia: Clinical Implications for the Pain Practitioner. Pain Physician, 12, 679-684. https://doi.org/10.36076/ppj.2009/12/679

[5] Lee, M., Silverman, S.M., Hansen, H., Patel, V.B. and Manchikanti, L.A. (2011) A Comprehensive Review of Opioid-Induced Hyperalgesia. Pain Physician, 14, 145-161. https://doi.org/10.36076/ppj.2011/14/145

[6] Leal, P.C., Clivatti, J., Garcia, J.B.S. and Sakata, R.K. (2010) Opioid Induced Hyperalgesia (HIO). Brazilian Journal of Anesthesiology, 60, 639-647. https://doi.org/10.1016/S0034-7094(10)70080-5

[7] Reznikov, I., Pud, D. and Eisenberg, E. (2005) Oral Opiod Administration and Hyperalgesia in Patientes with Cancer or Chronic Nonmalignant Pain. British Journal of Clinical Pharmacology, 60, 311-318. https://doi.org/10.1111/j.1365-2125.2005.02418.x 
[8] Célèrier, E., Rivat, C., Jun, Y., Laulin, J.P., Larcher, A., Reynier, P. and Simonnet, G. (2000) Long-Lasting Hyperalgesia Induced by Fentanyl in Rats: Preventive Effect of Ketamine. Anesthesiology, 92, 465-472. https://doi.org/10.1097/00000542-200002000-00029

[9] Mao, J. (2002) Opioid-Induced Abnormal Pain Sensitivity: Implications in Clinical Opioid Therapy. Pain, 100, 213-217.

https://doi.org/10.1016/S0304-3959(02)00422-0

[10] Simonnet, G. and Rivat, C. (2003) Opioid-Induced Hyperalgesia: Abnormal or Normal Pain? NeuroReport, 14, 1-7. https://doi.org/10.1097/00001756-200301200-00001

[11] Ossipov, M.H., Lai, J., King, T., Vanderah, T.W. and Porreca, F. (2005) Underlying Mechanisms of Pronociceptive Consequences of Prolonged Morphine Exposure. Peptide Science, 80, 319-324. https://doi.org/10.1002/bip.20254

[12] Gebhart, G.F. (2004) Descending Modulation of Pain. Neuroscience \& Biobehavioral Reviews, 27, 729-737. https://doi.org/10.1016/j.neubiorev.2003.11.008

[13] Vanderah, T.W., Ossipov, M.H., Lai, J., Malan Jr., T.R. and Porreca, F. (2001) Mechanisms of Opioid-Induced Pain and Antinociceptive Tolerance: Descending Facilitation and Spinal Dynorphin. Pain, 92, 5-9. https://doi.org/10.1016/S0304-3959(01)00311-6

[14] Ciobotaru, O.R., Lupu, M.N., Rebegea, L., Ciobotaru, O.C., Duca, O.M., Tatu, A.L., Voinescu, C.D., et al. (2019) Dexamethasone-Chemical Structure and Mechanisms of Action in Prophylaxis of Postoperative Side Effects. Revista de Chimie, 70, 843-847. https://doi.org/10.37358/RC.19.3.7017

[15] Koppert, W., Sittl, R., Scheuber, K., Alsheimer, M., Schmelz, M. and Schuttler, J. (2003) Differential Modulation of Remifentanil-Induced Analgesia and Potinfusion Hyperalgesia by S-Ketamine and Clonidine in Humans. Anesthesiology, 99, 152-159. https://doi.org/10.1097/00000542-200307000-00025

[16] Raffa, R.B., Pergolizzi, J.V.JR., Taylor Jr., R. and Ossipov, M.H. (2018) Nature's First "Atypical Opioids": Kratom and Mitragynines. Journal of Clinical Pharmacy and Therapeutics, 43, 437-441. https://doi.org/10.1111/jcpt.12676

[17] Koppert, W. (2004) Opioid-Induced Hyperalgesia. Pathophysiology and Clinical Relevance. Der Anaesthesist, 53, 455-466.

https://doi.org/10.1007/s00101-004-0669-1

[18] Pires, O.C., Dalcim, M.L., Pigozzi, A.L.M., Caldeira, F.M.S.L.A., Pires, M.H.R., Neto, L.A. and Posso, I.P. (2020) Effects of Duloxetine, Fluoxetine and Pregabalin on Fentanyl-Induced Hyperalgesia in Rattus Novergicus. Brazilian Journal of Pain, 3, 14-18. https://doi.org/10.5935/2595-0118.20200004

[19] Dupen, A., Shen, D. and Ersek, M. (2007) Mechanisms of Opioid-Induced Tolerance and Hyperalgesia. Pain Management Nursing, 8, 113-121. https://doi.org/10.1016/j.pmn.2007.02.004

[20] Joly, V., Richebe, P., Guignard, B., Fletcher, D., Maurette, P., Sessler, D.I. and Chauvin, M. (2005) Remifentanil-Induced Postoperative Hyperalgesia and Its Prevention with Small-Dose Ketamine. Anesthesiology, 103, 147-155. https://doi.org/10.1097/00000542-200507000-00022

[21] Ji, A. and Zhu, M. (2020) Effects of Curcumin on Biological Behavior and NF-kB/ TNF-a Pathway in Mice with Metastatic Bone Pain of Breast Cancer Induced by Walker 256 Cells. Journal of Cancer Therapy, 11, 339-350. https://doi.org/10.4236/jct.2020.116028 
[22] Armenian, P., Vo, K.T., Barr-Walker, J. and Lynch, K.L. (2018) Fentanyl, Fentanyl Analogs and Novel Synthetic Opioids: A Comprehensive Review. Neuropharmacology, 134, 121-132. https://doi.org/10.1016/j.neuropharm.2017.10.016 